\title{
Structure of intermediates of the water oxidation reaction in photosystem II
}

L. Lassalle ${ }^{1}$, J. Kern ${ }^{1}$, M. Ibrahim ${ }^{2}$, K. D. Sutherlin ${ }^{1}$, I.D. Young ${ }^{1}$, R. Chatterjee ${ }^{1}$, S. Gul ${ }^{1}$, F. Fuller $^{3}$, R. Hussein ${ }^{2}$, A. S. Brewster ${ }^{1}$, A. Bhowmick ${ }^{1}$, N. K. Sauter ${ }^{1}$, A. Zouni ${ }^{2}$, J. Messinger ${ }^{4,5}$, V. K. Yachandra ${ }^{1}$, J. Yano ${ }^{1}$

${ }^{1}$ Molecular Biophysics and Integrated Bioimaging Division, Lawrence Berkeley National Laboratory, Berkeley, CA 94720, USA.

${ }^{2}$ Institut für Biologie, Humboldt-Universität zu Berlin, D-10099 Berlin, Germany.

${ }^{3}$ LCLS, SLAC National Accelerator Laboratory, Menlo Park, CA 94025, USA.

${ }^{4}$ Institutionen för Kemi, Kemiskt Biologiskt Centrum, Umeå Universitet, SE 90187 Umeå, Sweden.

${ }^{5}$ Department of Chemistry - Ångström, Molecular Biomimetics, Uppsala University, SE 75237 Uppsala, Sweden.

Email Contact: 1lassalle@lbl.gov

Photosystem II (PSII) catalyzes the light driven oxidation of water into dioxygen, protons and electrons. This reaction takes place at the oxygen evolving complex (OEC) a $\mathrm{Mn}_{4} \mathrm{CaO}_{5}$ cluster, through five intermediate $\mathrm{S}$-states $\left(\mathrm{S}_{0}\right.$ to $\left.\mathrm{S}_{4}\right), \mathrm{S}_{1}$ being the dark-stable state and $\mathrm{S}_{3}$ the highest oxidized semi-stable state before $\mathrm{O}-\mathrm{O}$ bond formation and $\mathrm{O}_{2}$ evolution. We have been using fs X-ray pulses from an X-ray free electron laser (XFEL) to study the geometric and electronic structure of the OEC over the reaction cycle and recently reported high-resolution (around $2 \AA$ ) structures of PSII at room temperature for the four stable states in the S-state cycle as well as for two time points in the $\mathrm{S}_{2}-\mathrm{S}_{3}$ transition.

Our results reveal important structural changes including the binding of one additional 'water', Ox, during the $\mathrm{S}_{2} \rightarrow \mathrm{S}_{3}$ state transition. The binding of the additional oxygen Ox in the $\mathrm{S}_{3}$ state between $\mathrm{Ca}$ and $\mathrm{Mn} 1$ suggests $\mathrm{O}-\mathrm{O}$ bond formation mechanisms involving $\mathrm{O} 5$ as one substrate, where $\mathrm{Ox}$ is either the other substrate oxygen or is perfectly positioned to refill the $\mathrm{O} 5$ position during $\mathrm{O}_{2}$ release [1]. We also explored the extended network of $\mathrm{H}$-bonds between amino acid residues and waters connecting the OEC to the bulk solvent. We observed several significant changes in this network during the S-state cycle. Based on these data we will discuss the dynamics of the catalytic site and its environment over the reaction cycle.

Reference

1. Kern J, et al. (2018) Nature 563, 421 